\title{
Detection of breech presentation: Abdominal palpation and hand-held scanning by midwives
}

Joanna Keable, Kenda Crozier

Corresponding author Joanna.keable@jpaget.nhs.uk

\section{Abstract}

Background: The NHS Litigation Authority's 'sign up to safety' campaign aims to prevent undiagnosed breech birth and possible poor birth outcomes. An audit was completed following the introduction of hand-held scanning ultrasound examination.

Aims: The hand held ultrasound was used by midwives for all women in labour and before induction of labour to confirm presentation.

Methods: A criterion-based retrospective audit, conducted over 6 months in 2016, with a sample of 2737 women.

Findings: The audit demonstrated that 22 breech presentations were detected when using the handheld ultrasound before induction of labour or in labour. The audit standard of $100 \%$ of women receiving an ultrasound scan was not met, and potential reasons are explored. Conclusions The results support the use of hand-held ultrasound, as it did detect breech presentation before induction of labour or spontaneous labour and birth. Further work includes the audit of the reasons that hand-held ultrasound scanning was not used, to ensure that a targeted action plan can be created. Future research into midwifery values, cultural attitudes and the effectiveness of abdominal palpation is also needed, to develop the knowledge base on which scanning can be framed.

\section{Introduction}

The 'sign up to safety' initiative (NHS Litigation Authority, 2016) was introduced in 2016 to support improvements in care, and to reduce the number of stillbirths, as part of the Royal College of Obstetricians and Gynaecologists (RCOG) 'Each Baby Counts' programme (RCOG, 2016).

The RCOG green top guideline (Impey et al 2017) cites the risk of perinatal mortality as $0.5 / 1000$ for an elective breech caesarean section at 39 weeks gestation, $2 / 1000$ for a planned vaginal breech birth, and 1/1000 for a planned cephalic birth. A planned vaginal breech birth therefore has twice the risk of a planned cephalic birth and one-and-a-half times the risk of the caesarean section. However, the guideline also states that planned vaginal breech birth is nearly as safe as the cephalic birth with skilled birth attendants. It also states that there is an increased risk of maternal complications with emergency caesarean section as well as the long-term reproductive complications. The risks associated with breech diagnosed late in pregnancy or during labour include the highest rates of emergency caesarean section (64\%), cord prolapse (1.4\%) and the poorest infant outcomes (Gallagher et al, 2009). Planning the breech birth appears to be key, and the use of handheld ultrasound scanning in midwifery could also support unbiased counselling. 
The RCOG campaign was the stimulus for the introduction of hand-held ultrasound examination at Norfolk and Norwich University Hospital NHS Foundation Trust, which primarily aimed to identify breech presentation to improve outcomes. A risk-benefit analysis was completed by the Clinical Director and the Head of Legal Services, which led to midwives using hand-held scanners to confirm breech presentation.

\section{Literature Review}

A literature search was carried out both in relation to the aim of the study and for the implications in midwifery practice. Literature relevant to improving outcomes found that 3-4\% of pregnant women carried a breech baby to term and that $10 \%$ of those were not detected until labour (RCOG, 2016; Impey et al, 2017).

Webb et al (2011) found that abdominal palpation, as a means to correctly identify the left occiput anterior fetal position (cephalic or 'head down' position), at labour onset was poor. They suggested that ultrasound scanning may be valuable to complement abdominal palpation at the onset of labour. The researchers discussed the notion that a reliance on ultrasound had reduced midwifery skill, suggesting that community midwives were more accurate with abdominal palpation, which they relied on out of necessity. They concluded that the routine use of ultrasound on labour wards might become necessary. The researchers considered the impact of bias based on maternal and midwifery characteristics, sample size and delay on verification of fetal position, which may, if completed at the time of palpation, have shown the same fetal position.

Edvardsson et al (2015) researched the views of midwives in Australia on the use of ultrasound during pregnancy. They found that ultrasound scanning was seen as having advantages, but was also perceived to contribute to increased medicalisation of pregnancy. The authors found that ultrasound was normalised and unquestioned in healthcare and that, while midwives prioritised maternal health, pregnant women put fetal interests ahead of their own. The authors also found that ultrasound had the potential to undermine the normal pregnancy and childbirth process, and was said to be trusted over clinical skills, partly due to the 'evidence' that could be provided. The midwives in the study described feeling that it was increasingly necessary to use medical skills to confirm midwifery skills, which they interpreted as negative. Midwives also felt unable to take full advantage of their skills to provide a nurturing atmosphere to support normal birth.

Increased technology could lead the mother and/ or the midwife to rely more on a birth environment dependent on technology in order to support decision- making. Huang et al (2012) found that, in rural China, greater use of ultrasound scanning was associated with higher caesarean section rates (54.8\%), although they failed to identify choice of birth at booking and so had to rely on women's recall. Harris et al (2015) did document place of birth at booking, and found that ultrasound was not associated with the decision, although their sampling and methodology led to results and conclusions that neither supported nor disproved the notion of ultrasound leading to increased medicalisation. These articles assumed that medicalisation was a negative construct, when in fact, it appeared to depend on whether the respondent was a midwife, woman or obstetrician.

\section{Method}

\section{Audit setting and objectives}

Norfolk and Norwich University Hospital NHS Foundation Trust is a large teaching hospital with approximately 6000 births per year, and approximately 200 midwives working across the hospital and the community. In a 9-month period in 2015, six women 
with an unknown breech presentation were induced and eight had an undiagnosed vaginal breech birth. Hand- held ultrasound devices were introduced as routine care for all women presenting in labour at term in the midwife-led birthing unit (MLBU) and in the labour ward, and when admitted for induction of labour to the antenatal ward. The devices were funded by the 'sign up to safety' initiative. All midwifery staff who were working on antenatal ward, labour ward and MLBU were trained in their use and documentation. Information for service users on the use of ultrasound scanning was provided on admission to the hospital. Following the introduction of hand-held ultrasound, a criteria-based, restrospective audit was conducted to establish:

- That all women who attended in labour had a hand- held ultrasound scan of presentation

- That there was documentation to show that a presentation scan had been performed

- That induction of labour did not occur with a term breech fetus.

Ethical approval was obtained from the Faculty of Medicine and Health Sciences Ethics Committee at the University of East Anglia. The project was supported by the Head of Midwifery, Clinical Director and Departmental Manager of Women and Children at the Trust. The audit was registered with the local Trust audit board. The audit was designed, from the beginning, to protect patient confidentiality: once data were collected, they were immediately anonymised by assigning an audit number. The number of staff aware of the patient-identifiable data was limited to two, and the data set was analysed and stored on Trust information technology systems. Identifiable data was not included in the final report. Patient consent was not sought as this was a retrospective audit and patient care was not being affected by inclusion.

\section{Method}

The retrospective audit began in April 2016 and lasted for 6 months. Quantitative data were sourced from computer records, namely a database system in which the admitting and/or delivering midwife enters the woman's care episode. Paper records were also used if further information was required to clarify ambiguity.

Inclusion criteria for women in this study were:

Term pregnancy (37-42 weeks)

Singleton pregnancy

in labour

Induction of labour

Consented to ultrasound by a midwife.

The sample numbered 2737 women, who were divided into spontaneous labour $(n=1510)$ and induction of labour ( $n=1227$ ). Women were excluded from the audit if there was a multiple pregnancy, if they did not consent to ultrasound or if they presented in preterm labour (less than 37 weeks' gestation). During the course of the audit, women discussed birth choices with the senior registrar, and the results demonstrated that all women presenting for induction of labour chose an elective caesarean section if breech presentation was detected. The maternity department also had a midwife- led clinic, where midwives saw women to diagnose breech presentation late in pregnancy and offer external cephalic version. These data were not part of the audit. Women who wished to opt for a vaginal breech birth were also seen at the clinic by the consultant obstetrician.

\section{Results}

Over the 6-month audit period, 585 women of 1510 (38.7\%) presenting in spontaneous labour received ultrasound scanning (Table 1). There were a total of seven breech presentations detected 
during this time. The outcomes for those women who had a breech detected by hand-held ultrasound scanning were two vaginal breech births (Apgars were normal and the babies were not admitted to neonatal intensive care), three elective lower segment caesarean sections and two emergency lower segment caesarean sections.

An important outcome of this audit was the identification of breech presentation where women were attending for induction of labour. Table 2 shows that, of the hand-held ultrasound scans performed, 15 breech presentations were identified (all women in this group went on to have an elective lower segment caesarean section). Only $68 \%$ of women were scanned overall, but this percentage increased from April to September. Comparison of spontaneous labour scanning to induction of labour scanning (Tables 1 and 2) shows that a higher proportion of women attending for induction of labour received hand-held ultrasound scanning than women who attended in spontaneous labour. As induction of labour primarily occurs on the antenatal ward, this suggests that hand-held ultrasound was used there more than the labour ward or the MLBU. From the existing data collection, it was not possible to analyse where the hand-held ultrasound scanner was most in use, between the MLBU or the labour ward.

A total of 2453 women received abdominal palpation between April and September 2016 (Table 3). Of these, 1164 (47\%) had hand-held ultrasound performed for presentation. The target of $100 \%$ of women having ultrasound by handheld device was not met. Following hand-held ultrasound, 28 women $(2.4 \%)$ were identified as having a breech presentation, in comparison to $45(1.8 \%)$ who had already received this diagnosis using abdominal palpation. This seems to indicate that abdominal palpation is less accurate than hand-held ultrasound. The data in Table 3 also included women who were scanned at term for other reasons, most commonly pre-labour rupture of membranes and decreased fetal movements. These data were included to analyse the effectiveness of hand-held scanning in relation to abdominal palpation.

Table 4 shows that 1504 (61\%) women had a normal vaginal birth during 6 months of 2016, and 2409 women (65\%) over 9 months in 2015. The combined totals for spontaneous vaginal breech birth and emergency caesarean section for breech represented less than $1 \%$ of all births in 2016.This was also the case in 2015, meaning that there was no change between spontaneous and emergency lower segment caesarean section rates for breech presentation since the use of the hand-held scanner was introduced. Emergency caesarean section (cephalic presentation) was $9.4 \%$ in 2015 and $13 \%$ in 2016, representing a small increase of 3.6\%. Instrumental cephalic births were $12 \%$ in 2015 and 2016, and caesarean section $13 \%$ in both years, representing a stable rate. Combining the elective and emergency caesarean section percentages gives a figure of $22.4 \%$ in 2015 and $26 \%$ in 2016. This is comparable to the national average of $26.2 \%$ (Winter, 2015); however, it represents an increase for this particular maternity unit.

\section{Discussion}

Before the audit, all the staff were trained in the required skills to use the hand-held scanner, with doctors involved in supporting their use. As the audit did not meet the target of $100 \%$ of women receiving hand-held ultrasound scanning, the analysis and subsequent action plan must include an assessment of the underlying reasons for non- compliance. At commencement of the audit, 94 midwives were trained; this figure grew as the audit progressed and may well reflect the increase in the results.

The training plan involved daily hand-held scanning workshops for midwives over a 3-month period. The workshops comprised 1 hour of theory and discussion, followed by practice on the wards with consenting women. The midwives completed a competency logbook, detailing both successful and 
unsuccessful cases. Following the initial workshops, the training was cascaded by the 'midwife champions' in each department. The champions were midwives deemed competent and assessed as suitable for cascade training, or who had other ultrasound qualifications. Newly-qualified midwives attended workshops as part of their preceptorship training, while bank midwives were supplied with the guideline, competency and logbooks and advised to work with a midwife champion.

An obvious problem with the training was that it was not mandatory: midwives were expected to attend in their own time and claim the time back. This may have made it difficult for clinical midwives to attend, and may not have been a priority for them. To ensure compliance, training must be mandatory and included in the training needs analysis for the department. The training and skills can then be recorded in the training compliance report for each department and for each individual midwife, enabling managers to monitor and support the training with protected time. These changes would need to be included in the governance structure and approved by the Head of Midwifery. There are multiple reasons for the use of technology in healthcare, including changing societal acceptance of everyday technology (Parkin, 2009) and consumer demand. Midwifery philosophies and obstetric practices are often seen as separate, with normality in pregnancy and childbirth being the central tenet in midwifery. The use of technology is considered by midwives as interfering with normality; however, research has shown that service users do not share that view (Edvardsson et al, 2015).

Not all the women audited received a scan, and midwives' views of their own technological competence may have prevented the use of the technology (Porter et al, 2007).

The hand-held ultrasound scan was used more on the antenatal ward than on the MLBU and labour ward. As most induction of labour happens on the antenatal ward, this finding may demonstrate that the increased use of the hand held scanner on the antenatal ward had the greatest effect in preventing unplanned breech birth from induction of labour. This may be because different cultures exist in each of the areas, reflecting the different typologies among midwives; however, further qualitative research studies are required.

The reasons for not reaching the audit standard were explored (Table 5): the primary reason was that the practice was not embedded and the secondary reason was related to documentation, both electronic and paper-based, due to a lack of involvement of the key stakeholders.

\section{Conclusion}

The audit results support the use of the hand-held ultrasound by midwives, as it detected breech presentation in labour and before induction of labour, although the audit target for scanning was not achieved. The reasons for not using hand-held ultrasound were not captured, and having this information would have identified the local barriers to the use of hand-held ultrasound to form a targeted action plan to improve the rate of scanning.

The Trust continues to support the use of hand-held ultrasound scanning, and an action plan was drawn up to increase use following an exploration of the reasons for non-compliance among midwives. The plan includes more detailed information for women on the use of hand-held ultrasound devices. If women know to request this method of assessment when they attend hospital, use among midwives is likely to increase.

Future research must involve all stakeholders from the beginning. Funding for the project has now ended; therefore, a re-audit will need to be planned with consideration for the barriers of clinical workload. Further improvements would include separating the clinical areas to evaluate if there is any difference between the MLBU and the labour ward.

Recommendations include auditing the use of both hand-held ultrasound and abdominal palpation. This audit also raises the question of the usefulness of abdominal palpation as a screening tool, 
although there are benefits of the skill, such as improving the quality of the communication between the midwife and the woman.

Both the literature and the results of this audit raise the need for further research into the midwife's role in scanning technology. The existing system is fragmented, resulting in women attending multiple appointments with a range of medical and allied health professionals, which may lead to variation in decision-making and potential confusion and anxiety for the woman. If the midwifery role encompasses scanning, the service could be made more efficient, effective and safe. The Nursing and Midwifery Council (NMC) Code (NMC, 2015) places a duty to accurately assess and to refer in a timely way to a suitably qualified practitioner (in this case, the midwife), who could be trained to assess breech presentation using hand-held ultrasound. The challenge is to be 'with woman' in the environment of her choice, while being able to use available technology competently. Wider implications include the effect of scanning or hand-held ultrasound on the midwifery role, including the impact on resources in terms of training, funding and maintenance. NHS England (2016) and the Perinatal Institute (2017) aim to prevent stillbirth and promote safety by using ultrasound, among other strategies, to detect at-risk babies. These strategies also require funding and resourcing, an ethical dilemma for healthcare economics.

Audit was the best method of investigating hand-held ultrasound after it had been implemented as routine practice. Its measurement of outcomes was reliable and did not require randomisation. Although this was not research, a high standard of data collection and analysis was carried out, leading to improvements in care. Future research to support the recommendation includes exploring midwifery values and cultural attitudes so that hand-held ultrasound scanning can be effectively taught and introduced into clinical practice. Research into the effectiveness of abdominal palpation is limited, so it would be an improvement to increase this knowledge base on which scanning can be developed.

\begin{tabular}{|l|}
\hline Key Points \\
\hline The audit of handheld ultrasound demonstrated it was effective at confirming breech \\
presentation. \\
\hline The skill of using Handheld ultrasound can be learned by midwives and used to support the \\
practise of abdominal palpation. \\
\hline $\begin{array}{l}\text { The use of handheld ultrasound by midwives was variable depending on place of work ( antenatal } \\
\text { ward, labour ward or midwife led birthing unit. }\end{array}$ \\
\hline $\begin{array}{l}\text { Further research is required into the midwife's role in relation to scanning, the effectiveness of } \\
\text { abdominal palpation and the woman's perception. }\end{array}$ \\
\hline
\end{tabular}

Declaration of interests: The authors have no conflicts of interest to declare.

Ethical approval: Ethical approval was obtained from the Faculty of Medicine and Health Sciences Ethical Committee at the University of East Anglia.

Funding: Funding for this study was provided by the NHS Litigation Authority.

Acknowledgement: The authors would like to thank the midwives of the NNUH; consultant obstetrician Mr Martin Cameron; NNUH Audit Department; and one heavily pregnant best friend who acted as a training model! 



\section{References}

Edvardsson K, Mogren I, Lalos A, Persson M, Small R. A routine tool with far-reaching influence: Australian midwives' views on the use of ultrasound during pregnancy. BMC Pregnancy Childbirth. 2015; 15(1):195. https://doi.org/10.1186/s12884- 015-0632-y

Gallagher A, Kelly-Scammell A, Hammersley B. P237 Undiagnosed breech presentation in labour at term: is it time to consider routine presentation scanning? Int J Gynaecol Obstet. 2009; 107: S480. https://doi.org/10.1016/S0020- 7292(09)61727-6

Harris JM, Franck L, Green B, Wilson S, Michie S.The relationship between frequency of obstet-ric ultrasound scans and birthplace preference - A case control study. Midwifery. 2015; 31(1): 31-6. https://doi.org/10.1016/j. midw.2014.05.006

Huang K,Tao F, Raven J, Liu L,Wu X,Tang S. Utilization of antenatal ultrasound scan and implications for caesarean section: a cross-sectional study in rural Eastern China. BMC Health Serv Res. 2012; 12: 93. https://doi. org/10.1186\%2F1472-6963-12-93

Impey LWM, Murphy DJ, Griffiths M, Penna LK, on behalf of the Royal College of Obstetricians and Gynaecologists. Management of breech presentation. BJOG. 2017. https:// doi.org/10.1111/14710528.14465

NHS England. Saving Babies' Lives: A care bundle for reducing stillbirth. London: NHS England; 2016

NHS Litigation Authority. Spotlight on Maternity: Contributing to the Government's national ambition to halve the rates of stillbirths, neonatal and maternal deaths and intrapartum brain injuries by 2030. London: NHS Litigation Authority; 2016

Nursing and Midwifery Council.The Code: Professional standards of practice and behaviour for nurses and midwives. London: NMC; 2015

Parkin P. Managing change in healthcare: Using action research. London: Sage Publications; 2009 Perinatal Institute. Perinatal news. 2017. https://perinatal.org. uk/Perinatal_Newsletter_Autumn_2017.pdf (accessed 1 May 2018)

Porter S, Crozier K, Sinclair M, Kernohan WG. New midwifery? A qualitative analysis of midwives decision-making strategies. J Adv Nurs. 2007; 60(5): 525-34. https://doi.org/10.1111/ j.13652648.2007.04449.x

Royal College of Obstetricians and Gynaecologists. Each Baby Counts: key messages from 2015. London: RCOG; 2016

Webb SS, Plana MN, Zamora J et al. Abdominal palpation to determine fetal position at labor onset: a test accuracy study. Acta Obstet Gynecol Scand. 2011; 90(11): 1259-66. https:// doi.org/10.1111/j.1600-0412.2011.01226.x

Winter J. Hospital Episode Statistics: NHS Maternity Statistics 2013-2014. 2015. http://content.digital.nhs.uk/catalogue/ PUB16725/nhs-mate-eng-2013-14-summ-repo-rep.pdf (accessed 1 May 2018) 
Tables and Figures

Table 1 Number of women presenting in labour scanned using HHUS April - Sept 2016

\begin{tabular}{|l|l|l|l|l|}
\hline Month & $\begin{array}{l}\text { Spontaneous } \\
\text { labour }\end{array}$ & $\begin{array}{l}\text { Hand held } \\
\text { ultrasound }\end{array}$ & $\%$ & $\begin{array}{l}\text { Number of } \\
\text { Breech } \\
\text { presentations } \\
\text { detected }\end{array}$ \\
\hline April & 252 & 63 & 25 & 0 \\
\hline May & 257 & 76 & 30 & 1 \\
\hline June & 234 & 87 & 37 & 0 \\
\hline July & 260 & 114 & 44 & 3 \\
\hline August & 269 & 122 & 45 & 2 \\
\hline September & 238 & 123 & 52 & 1 \\
\hline & & & & 7 \\
\hline Total & 1510 & 585 & 38.7 & \\
\hline
\end{tabular}

Table 2 Number of women presenting for induction of labour scanned using HHUS April Sept 2016

\begin{tabular}{|l|l|l|l|l|}
\hline Month & $\begin{array}{l}\text { Induction of } \\
\text { labour }\end{array}$ & $\begin{array}{l}\text { Hand held } \\
\text { ultrasound }\end{array}$ & $\%$ & $\begin{array}{l}\text { Number of } \\
\text { Breech } \\
\text { presentations } \\
\text { detected }\end{array}$ \\
\hline April & 133 & 62 & 46.6 & 0 \\
\hline May & 141 & 96 & 68.0 & 1 \\
\hline June & 116 & 77 & 66.3 & 1 \\
\hline July & 144 & 101 & 70.1 & 5 \\
\hline August & 125 & 104 & 83.2 & 1 \\
\hline September & 159 & 121 & 76.1 & 7 \\
\hline & & & & 15 \\
\hline Total & 818 & 561 & 68.0 & \\
\hline
\end{tabular}


Table 3 Findings from abdominal palpation and HHUS April - Sept 2016

\begin{tabular}{|l|l|l|l|l|l|l|}
\hline \multirow{2}{*}{ Month } & \multicolumn{3}{|l|}{ Abdominal palpation $(\mathrm{n}=2453)$} & \multicolumn{3}{l|}{ Handheld Ultrasound Scan $(\mathrm{n}=1164)$} \\
\cline { 2 - 7 } & Cephalic & Breech & Transverse & Cephalic & Breech & Transverse \\
\hline April & 377 & 3 & 0 & 110 & 0 & 0 \\
\hline May & 393 & 2 & 0 & 171 & 1 & 0 \\
\hline June & 348 & 0 & 0 & 165 & 5 & 0 \\
\hline July & 413 & 7 & 0 & 212 & 5 & 0 \\
\hline August & 439 & 18 & 1 & 229 & 9 & 0 \\
\hline September & 435 & 15 & 2 & 248 & 8 & 1 \\
\hline & 2405 & 45 & 3 & 1135 & 28 & 1 \\
\hline
\end{tabular}

Table 4 Birth Outcomes following Introduction of Handheld Ultrasound

CS - Caesarean section

LSCS Lower segment caesarean section

\begin{tabular}{|l|l|l|}
\hline Birth outcome & 2015 ( 9 months) & 2016 ( 6 months) \\
\hline Normal Vaginal Birth & 2409 & 1504 \\
\hline Induction of labour breech & 6 & 0 \\
\hline Vaginal Breech birth & 8 & 5 \\
\hline Emergency CS breech & 24 & 11 \\
\hline Emergency CS cephalic & 353 & 323 \\
\hline Emergency CS transverse & 2 & 1 \\
\hline Instrumental cephalic & 450 & 290 \\
\hline Vaginal Breech extraction & 1 & 0 \\
\hline Elective LSCS & 475 & 338 \\
\hline
\end{tabular}

Table 5 documentation of handheld ultrasound April - Sept 2016

\begin{tabular}{|l|l|l|l|}
\hline Month $\mathrm{n}$ & Documented n (\%) & Not documented n (\%) & Exception n (\%) \\
\hline April 445 & $114(25)$ & $209(47)$ & $122(27)$ \\
\hline May 478 & $175(37)$ & $184(38)$ & $119(25)$ \\
\hline June 427 & $168(39)$ & $184(38)$ & $75(18)$ \\
\hline July 467 & $220(47)$ & $150(32)$ & $97(21)$ \\
\hline August 462 & $238(52)$ & $41(9)$ & $183(40)$ \\
\hline September 458 & $260(57)$ & $141(31)$ & $57(12)$ \\
\hline Total 2737 & $1175(43)$ & $879(32)$ & $653(24)$ \\
\hline
\end{tabular}


